\title{
IMPLEMENTATION OF AN INTEGRATED THERMAL BUILDING MODEL FOR INVESTIGATIONS OF HEAT FLOWS
}

\author{
Maxim N. Morozov ${ }^{1, *}$, Alena O. Zhdanova ${ }^{1}$, and Maksim V. Piskunov ${ }^{1}$ \\ ${ }^{1}$ National Research Tomsk Polytechnic University, 634050 Tomsk, Russia
}

\begin{abstract}
A model of the building heating system, consisting of energy source, a distributed automatic control system, elements of individual heating unit and heating system is designed. Application Simulink of mathematical package Matlab is selected as a platform for the model. There are the specialized application Simscape libraries in aggregate with a wide range of Matlab mathematical tools allow to apply the "acausal" modeling concept. Implementation the "physical" representation of the object model gave improving the accuracy of the models.
\end{abstract}

\section{Introduction}

When creating complex models of a heating system, as a rule, the occurrence of difficulties is usually caused by following requirements (for example, to highlight works [1-6]):

1) simulation of individual components of building life support systems (for example, the control system, heating appliance, heat exchanger, etc.);

2) maintenance of model functioning in a wide temperature range.

Solution of the first problem is to find a compromise between the model description completeness and its adequacy and accuracy of studied system reproduction. The choice of internal and external influencing factors (which must be also adequately reproduced) variety is an important step in developing of the model. Excessive accuracy influences negatively on the capabilities of a computer, increasing simulation time. When solving the problem as a part of this work, there were used approaches, described in $[7,8]$.

Another no less important problem is to extend the temperature range of model operating. This is necessary condition for the investigation of district heating system reliability. The problem resides in narrow range of individual model component operating temperatures. For example, the temperature difference of the coolant reaches $90{ }^{\circ} \mathrm{C}$ during simulation. At temperatures of approximately $0{ }^{\circ} \mathrm{C}$, the decrease of modeling accuracy is inevitable. This problem is solved by optimization of thermal component models.

The aim of the present work is to develop a thermal model of the building.

\section{Research object}

\footnotetext{
* Corresponding author: tpu_chm@tpu.ru
} 
The object of research is a three-floored administration building (total area of $9870 \mathrm{~m}^{2}$ and volume of $35.926 \mathrm{~m}^{3}$ ) which is located in West Siberia (Tomsk city). Heat supply of the building is provided by the central heating unit at the temperature chart $95 / 70{ }^{\circ} \mathrm{C}$. The individual heating unit has been designed under the "independent scheme" [9]. Water is used as a coolant in the heating system internal circuit [10].

The thermal model of the building has been developed the actual operation of the building. The application Simulink of the mathematical package Matlab [11] has been selected as a platform for a model. Block-oriented approach has been applied to simulation and "visual" programming of building heating system in combination with a wide range of Matlab mathematical tools. An extension package Simscape, which implements a "physical" simulation concept [12], has also been applied to develop the model.

\section{Thermal model of building}

As a rule, thermal processes in buildings are described by mathematical equations, reflecting the heat transfer stationary mode. Upon that, heat flows are constant and don't depend on time, and thermal processes parameters (for example, coefficients of external and internal envelopments heat transfer, heat irradiation from heating appliance, etc.) are chosen from the reference literature.

In practice a stationary mode is observed only for a very limited time, due to constantly changing external disturbing factors. It is important to note, that the developed model considers dynamics of the real object functioning mode, as well as thermal processes nonlinearity and non-stationarity.

The law of energy conservation for a typical premise is at the basis of the thermal model of the building heating system there [7]:

$$
\begin{aligned}
& \mathrm{d} E_{\mathrm{a}} / \mathrm{d} t=Q_{\mathrm{hs}}-Q_{\mathrm{ec}} \\
& \left.E_{\mathrm{a}}=V_{\mathrm{a}} \cdot \rho_{\mathrm{a}} \cdot c_{\mathrm{a}} \cdot T_{\mathrm{a}}\right)
\end{aligned}
$$

where

$E_{\text {a }}$ internal energy of air in the premise [J]

$V_{\mathrm{a}}$ volume of air in the premise $\left[\mathrm{m}^{3}\right]$

$\rho_{\mathrm{a}}$ air density $\left[\mathrm{kg} / \mathrm{m}^{3}\right]$

$c_{\mathrm{a}}$ air heat capacity $[\mathrm{J} /(\mathrm{kg} \cdot \mathrm{K})]$

$T_{\mathrm{a}}$ air temperature in the premise $\left[{ }^{\circ} \mathrm{C}\right]$

$Q_{\mathrm{hs}}$ heat input to the premise from the heating system [W]

$Q_{\text {ec }}$ total heat loss of the premise through exterior envelopments [W]

During simulation, the following assumptions were accepted:

- specific heat capacity and density are characterized by constant values;

- coolant loss are lacked (equality of input and output expenditures);

- heat exchange with adjacent premises is lacked.

Considering the accepted assumptions, the law of energy conservation will be as follows:

$$
\begin{aligned}
& m_{\mathrm{a}} \cdot c_{\mathrm{a}} \cdot\left(\mathrm{d} T_{\mathrm{a}} / \mathrm{d} t\right)=Q_{\mathrm{hs}}-Q_{\mathrm{ec}} \\
& Q_{\mathrm{hs}}=g_{\mathrm{ha}} \cdot c_{\mathrm{ha}} \cdot\left(T_{1}-T_{2}\right)
\end{aligned}
$$

where

$m_{\mathrm{a}}$ mass of air, contained in the premise $[\mathrm{kg}]$ 
$g_{\text {ha }}$ coolant mass flow rate $[\mathrm{kg} / \mathrm{h}]$

$c_{\text {ha }}$ coolant heat capacity $[\mathrm{J} /(\mathrm{kg} \cdot \mathrm{K})]$

$T_{1}$ initial coolant temperature $\left[{ }^{\circ} \mathrm{C}\right]$

$T_{2}$ finite coolant temperature $\left[{ }^{\circ} \mathrm{C}\right]$

The following laws were applied to simulate different mechanisms of heat transfer between model components:

- Newton-Rikhman Law, describing the convective heat exchange:

$$
q_{\mathrm{K}}=k \cdot A \cdot \mathrm{d} T
$$

where

$q_{\mathrm{K}}$ heat flow $[\mathrm{W}]$

$k$ heat irradiation coefficient $\left[\mathrm{W} /\left(\mathrm{m}^{2} \cdot \mathrm{K}\right)\right]$

$A$ surface area of heat irradiation $\left[\mathrm{m}^{2}\right]$

$\mathrm{d} T$ temperature difference $\left[{ }^{\circ} \mathrm{C}\right]$

- Fourier's Law, describing the conductive heat exchange:

$$
q_{\mathrm{T}}=(\lambda / b) \cdot A \cdot \mathrm{d} T
$$

where

$q_{\mathrm{T}}$ is heat flow [W]

$\lambda$ is thermal conductivity coefficient $[\mathrm{W} /(\mathrm{m} \cdot \mathrm{K})]$

$b$ is layer thickness of heat exchange surface [m]

$A$ is surface area, perpendicular to heat flow $\left[\mathrm{m}^{2}\right]$

$\mathrm{d} T$ is temperature difference $\left[{ }^{\circ} \mathrm{C}\right]$

Model implementation in the Matlab package is based on representing of each individual functional component in the form of s-functions and subsystems blocks. In the process of simulation, the redistribution of heat flow is observed between sources, thermal energy transfer medium and its consumers.

Fig. 1-3 shows basic blocks of the developed thermal model of the district heating system of the building. The model comprises the following main functional components [8]:

- a heating appliance (radiator);

- a mixer tap;

- a valve;

- a thermal protection block of the premise;

- a weather block;

- a block of the premise temperature mode.

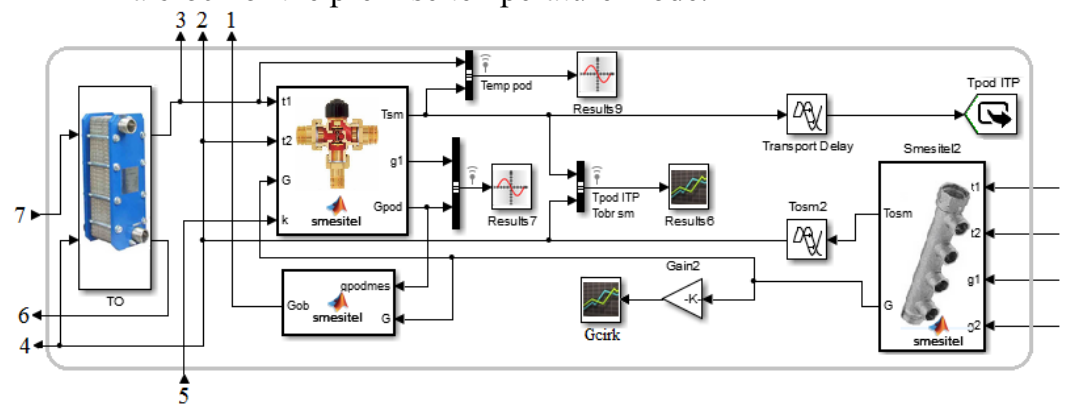

Fig. 1. The main thermal model blocks of the district heating system of the building: block of individual heating unit elements. 


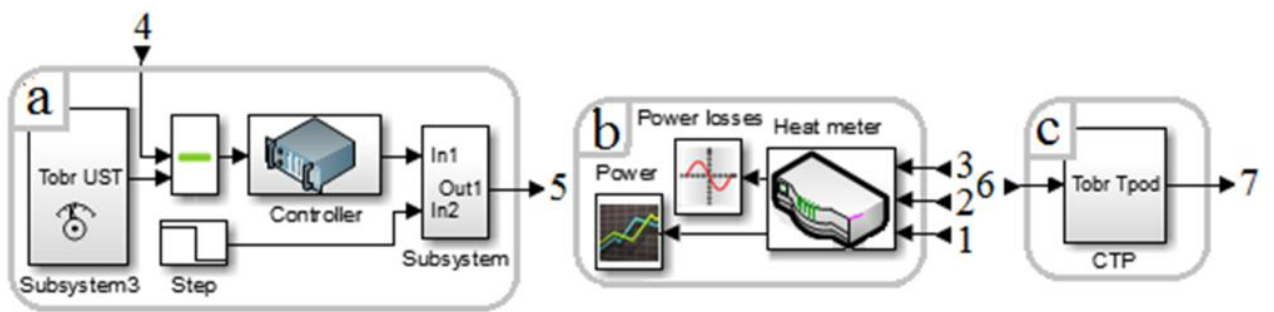

Fig. 2. The main thermal model blocks of the district heating system of the building: a - heat consumption controller, $\mathrm{b}$ - heat calculator, $\mathrm{c}$-heat supply source.

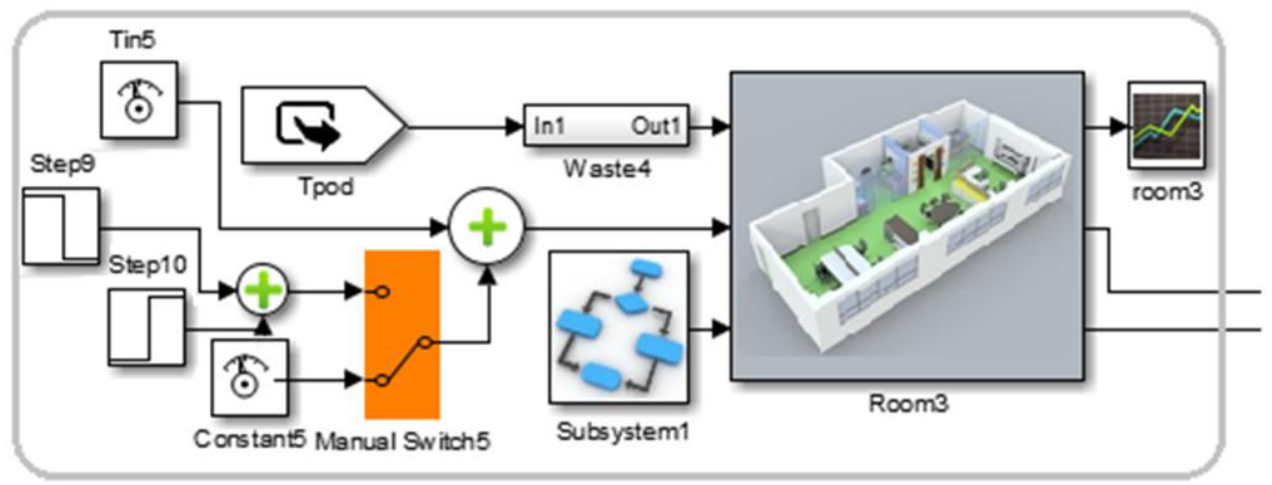

Fig. 3. The main thermal model blocks of the district heating system of the building: block of premise model.

\section{A heating appliance}

The process of heat transfer from the heating system coolant to the environment is carried out through the radiator case. Under that, different heat exchange mechanisms are involved:

1) convection and conductive heat exchange are realized at the "coolant - radiator wall" site;

2) heat transfer through the wall is carried out by thermal conductivity;

3) the "radiator wall - premise" site is characterized simultaneously by radiant heat exchange, convection and thermal conductivity.

Heat transfer rate of all of these sites reflects the total heat transfer coefficient $K_{\text {bat }}$.

In general, heat transfer simulation of a heating appliance is a complex problem that requires the use of mathematical physics methods to analyze the temperature distribution on the radiator surface. The most optimal approach at simulation is to use the average logarithmic temperature difference between the radiator surface and air inside the premise [7]:

$$
T_{\log }=\left(T_{1}-T_{2}\right) / \ln \left[\left(T_{1}-T_{\text {in }}\right) /\left(T_{2}-T_{\text {in }}\right)\right]
$$

where

$T_{1}$ coolant temperature at the radiator input $\left[{ }^{\circ} \mathrm{C}\right]$

$T_{2}$ coolant temperature at the radiator output $\left[{ }^{\circ} \mathrm{C}\right]$

$T_{\text {in }}$ temperature inside the premise $\left[{ }^{\circ} \mathrm{C}\right]$

The model of the heating appliance is based on the law of energy conservation:

$$
\begin{gathered}
m_{\mathrm{ha}} \cdot c_{\mathrm{ha}} \cdot\left(\mathrm{d} T_{2} / \mathrm{dt}\right)=Q_{\mathrm{hs}}-Q_{\mathrm{bat}} \\
Q_{\text {bat }}=K_{\text {bat }} \cdot A_{\text {bat }} \cdot T_{\text {log }}
\end{gathered}
$$


where

$m_{\text {ha }}$ weight of the coolant inside the radiator case $[\mathrm{kg}]$

$c_{\text {ha }}$ coolant heat capacity $[\mathrm{J} /(\mathrm{kg} \cdot \mathrm{K})]$

$Q_{\mathrm{hs}}$ heat input from the heating system coolant [W]

$Q_{\text {bat }}$ heat irradiation of the heating appliance [W]

$K_{\text {bat }}$ heat transfer total coefficient $\left[\mathrm{W} /\left(\mathrm{m}^{2} \cdot \mathrm{K}\right)\right]$

$A_{\text {bat }}$ heat irradiation surface area of radiator $\left[\mathrm{m}^{2}\right]$

Eq. (8) allows describing the change in coolant energy at radiator output (the left side of the equation), depending on balance between radiator heat input and heat irradiation (the right side).

Model implementation of the heating appliance using Simulink is shown in Fig. 4.

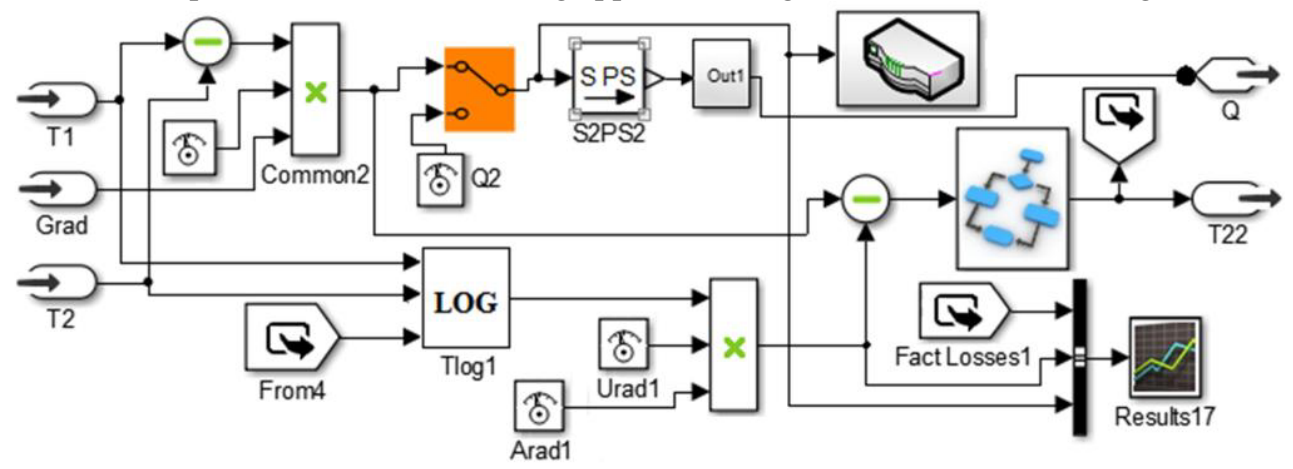

Fig. 4. A model of the heating appliance.

\section{A thermal protection block of the premise}

This block is a set of external envelopments (walls, windows, ceiling) models, as well as air inside the premise. The functioning of the block is described by the following equation:

$$
Q_{\mathrm{ec}}=\left[\left(K_{\mathrm{w}} \cdot A_{\mathrm{w}}\right)+\left(K_{\mathrm{c}} \cdot A_{\mathrm{c}}\right)+\left(K_{\mathrm{wd}} \cdot A_{\mathrm{wd}}\right)\right] \cdot\left(T_{\mathrm{in}}-T_{\mathrm{ext}}\right)
$$

where

$Q_{\text {ec }}$ total premise heat loss through external envelopments [W]

$T_{\text {in }}$ air temperature inside the premise $\left[{ }^{\circ} \mathrm{C}\right]$

$T_{\text {ext }}$ outside air temperature $\left[{ }^{\circ} \mathrm{C}\right]$

$K_{\mathrm{i}}$ total heat transfer coefficient $\left[\mathrm{W} /\left(\mathrm{m}^{2} \cdot \mathrm{K}\right)\right]$

$A_{i}$ surface area of envelopments $\left[\mathrm{m}^{2}\right]$

Indexes w, c, wd of parameters $K_{i}$ and $A_{i}$ means respectively wall, ceiling and window.

Given equation permit determining the total heat loss of the premise and is used at the Eq. (3). In turn, the total coefficient of single-layer construction heat exchange is determined by geometric and thermophysical characteristics:

$$
\frac{1}{k_{i}}=\frac{1}{k_{i} i n}+\frac{b_{i}}{\lambda_{i}}+\frac{1}{k_{i} a x t}
$$

where

$k_{\mathrm{i}}$ in heat irradiation coefficient on the inner surface $\left[\mathrm{W} /\left(\mathrm{m}^{2} \cdot \mathrm{K}\right)\right]$

$k_{\mathrm{i}}$ ext heat irradiation coefficient on the outer surface $\left[\mathrm{W} /\left(\mathrm{m}^{2} \cdot \mathrm{K}\right)\right]$

$b_{i}$ layer thickness of a heat exchange surface $[\mathrm{m}]$

$\lambda_{i}$ thermal conductivity coefficient of layer $[\mathrm{W} /(\mathrm{m} \cdot \mathrm{K})]$

According to the law of energy conservation (by analogy to the Eq. (3)), the thermal inertia of envelopments is considered in the block, at that, characteristics such as weight, 
heat capacity and the initial temperature of constructions elements are used. Block implementation using Simulink is shown in Fig. 5.

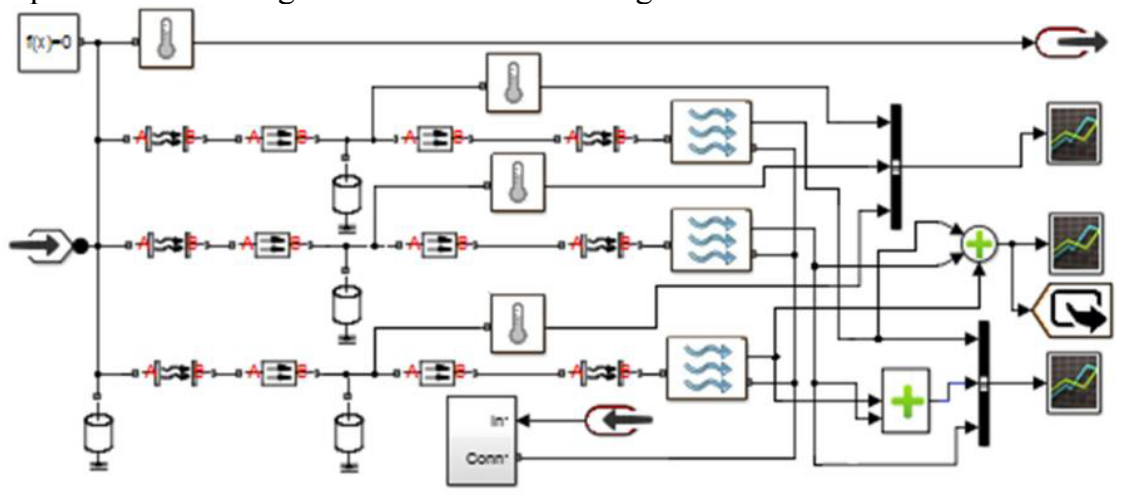

Fig. 5. A model of the block of the heating protection of the premise.

\section{Summary}

A model of the district heating system of the building, which allows investigating the stability of typical buildings and constructions thermal mode (to analyze cooling processes of the heating system coolant, air temperature reduction in premises of various configurations, as well as exterior envelopments) during heat supply failure, has been developed. It is also possible to use the model for energy efficiency investigation of different buildings.

The reported study is supported by the Russian Foundation for Basic Research RFBR (contract 16-38-00628).

\section{References}

1. M. Wallace, R. McBride, S. Aumi, P. Mhaskar, J. House, T. Salsbury, Chem. Eng. Sci. 69, 45 (2012)

2. S. Privara, Z. Vana, E. Zacekova, Energ. Buildings 55, 341 (2012)

3. M.A. Mishin, Polzunovskii vestnik 1, 146 (2010)

4. V.V. Burstev, A.S. Basi, N.M. Baitinger, Polzunovskii vestnik 1, 147 (2004)

5. A.V. Pugovkin, S.V. Kuprekov, D.V. Abushkin, I.A. Zarechnaya, N.I. Muslimova, Lectures of TUSUR University: Control, computing equipment 22, 293 (2010)

6. M. Maasoumy, M. Razmara, M. Shahbakhti, A.S. Vincentelli, Energ. Buildings 77, 377 (2014)

7. P. Lauenburg, J. Wollerstrand, Proceedings of the 11th International Building Performance Simulation Association Conference, 150 (Glasgow, Scotland, 2009)

8. T. Persson, Proceedings of the 45th International Conference of Scandinavian Simulation Society, 199 (Copenhagen, Denmark, 2004)

9. M. Zago, A. Casalegno, R. Marchesi, F. Rinaldi, Energies 4, 2115 (2011)

10. O. Ibrahim, F. Fardoun, R. Younes, H. Louahlia-Gualous, Build. Environ. 72, 259 (2014)

11. M. Kiyan, E. Bingöl, M. Melikoglu, A. Albostan, Energy Convers. Manage. 72, 147 (2013) 